\title{
Wild-Type Huntingtin Protects from Apoptosis Upstream of Caspase-3
}

\author{
Dorotea Rigamonti, ${ }^{1}$ Johannes H. Bauer, ${ }^{2}$ Claudio De-Fraja, ${ }^{1}$ Luciano Conti, ${ }^{1}$ Simonetta Sipione, ${ }^{1}$ \\ Clara Sciorati, ${ }^{3}$ Emilio Clementi, ${ }^{3,4}$ Abigail Hackam, ${ }^{5}$ Michael R. Hayden, ${ }^{5}$ Yong Li, ${ }^{2}$ Jillian K. Cooper, ${ }^{6}$ \\ Christopher A. Ross, ${ }^{6}$ Stefano Govoni, ${ }^{7}$ Claudius Vincenz,, ${ }^{2}$ and Elena Cattaneo ${ }^{1}$
}

\begin{abstract}
1'Institute of Pharmacological Sciences, University of Milano, 20133 Milano, Italy, ${ }^{2}$ Department of Pathology, University of Michigan, Ann Arbor, Michigan 48109-0726, 3Department of Biotechnology, San Raffaele Hospital, Milano, Italy,

4 Department of Pharmacobiology, University of Calabria, 87036 Rende, Italy, ${ }^{5}$ University of British Columbia, V52 4H4 Vancouver, British Columbia, Canada, ${ }^{6}$ Department of Psychiatry, Johns Hopkins University, Baltimore, Maryland 21025, and 7 Institute of Pharmacology, University of Pavia, 27100 Pavia, Italy
\end{abstract}

Expansion of a polyglutamine sequence in the $\mathrm{N}$ terminus of huntingtin is the gain-of-function event that causes Huntington's disease. This mutation affects primarily the medium-size spiny neurons of the striatum. Huntingtin is expressed in many neuronal and non-neuronal cell types, implying a more general function for the wild-type protein. Here we report that wild-type huntingtin acts by protecting CNS cells from a variety of apoptotic stimuli, including serum withdrawal, death receptors, and

Huntington's disease (HD) is an autosomal neurodegenerative disorder caused by a (CAG)n expansion in the gene IT15 (Huntington's disease Collaborative Research Group, 1993). This trinucleotide expansion encodes for a polyglutamine $\left(Q_{N}\right)$ stretch in the encoded protein, huntingtin ( $\mathrm{Htt})$, resulting in progressive neuronal death with clinical symptoms of chorea and dementia (Ross et al., 1997). Studies on the cellular localization of the mRNA and protein have revealed that wild-type (wt) and mutated (mu) Htt are expressed throughout the nervous system as well as in non-neuronal cells (Sharp and Ross, 1996). Despite this widespread distribution, only specific neurons in the striatum and cortex are affected in HD (Vonsattel et al., 1985; Kowall et al., 1987). The cytotoxicity of the mu protein is believed to be caused by a gain-of-function effect induced by the presence of the expanded CAG (for review, see MacDonald and Gusella, 1996).

The molecular mechanism by which the poly-Q expansion triggers cell death is not understood (Reddy et al., 1999). Intra-

\footnotetext{
Received Oct. 29, 1999; revised March 2, 2000; accepted March 2, 2000.

This work was supported by the Huntington's Disease Society of America (HDSA), the Hereditary Disease Foundation (HDF), Telethon (Italy \#E840), and Consiglio Nazionale delle Ricerche (Italy, \#98.01050.CT04) to E.C., National Institutes of Health Grants ROI E50811 and DAMD 17-96-1-6085 to C.V., and National Institutes of Health Grant NS16375 to C.A.R. The support of the Istituto Bancario San Paolo di Torino (Agenzia 8, Milano) to E.C. is also acknowledged. A special thanks to the members of the HDSA and HDF for their constant and strong encouragement and to the Associazione Italiana Corea di Huntington (AICH) for their interest in our work. We thank Drs. Michelle Ehrlich and Samgram Sisodia for critical discussion and comments on this manuscript. We also thank Dr. Alnemri E. for providing the active caspase-3 construct, Mara Monetti for help with cell culture work, and Ann-Marie DesLaurier for help with the FACS analysis. E.C., M.R.H., and C.A.R. are members of the "Coalition for the Cure" (HDSA). E.C. is also a member of the "Cure Initiative" (HDF).

D. R. and J. B. contributed equally to this work.

Correspondence should be addressed to Dr. Elena Cattaneo, Institute of Pharmacological Sciences, University of Milano, Via Balzaretti 9, 20133 Milano, Italy. E-mail: elena.cattaneo@unimi.it.

Copyright (C) 2000 Society for Neuroscience $\quad 0270-6474 / 00 / 203705-09 \$ 15.00 / 0$
}

pro-apoptotic Bcl-2 homologs. This protection may take place at the level of caspase- 9 activation. The full-length protein also modulates the toxicity of the poly- $Q$ expansion. Cells expressing full-length mutant protein are susceptible to fewer death stimuli than cells expressing truncated mutant huntingtin.

Key words: huntingtin; CAG; caspases; survival; CNS cells; Huntington's disease

cellular inclusions may be involved, but it is not clear whether they have a direct role in pathogenesis or are involved in progression (Davies et al., 1997; Di Figlia et al., 1997; Saudou et al., 1998) (for review, see Kim and Tanzi, 1998; Sisodia, 1998; Gutekunst et al., 1999; Hodgson et al., 1999). Proteolytic cleavage has been implicated by the findings of $\mathrm{N}$-terminal fragments in inclusions and the fact that Htt is a caspase substrate and is actively cleaved during apoptosis in cultured cells (Goldberg et al., 1996; Davies et al., 1997; DiFiglia et al., 1997; Wellington et al., 1998; Kim et al., 1999). Experiments performed in primary striatal neurons showed that the poly-Q cytotoxicity can be inhibited by the anti-apoptotic protein Bcl-X1 and caspase inhibitors (Saudou et al., 1998). Involvement of caspases is also indicated by the observation that dominant negative caspase-1 delays disease progression in transgenic mice (Ona et al., 1999). Studies using an isolated poly-Q sequence have suggested that the first pathogenic event is the aggregation and activation of caspase-8 (Sanchez et al., 1999). Finally, activation of caspase-3 and caspase-9 was reported in HD lymphoblasts (Sawa et al., 1999).

Much less is known about the physiological roles of wtHtt. Mice with a targeted disruption of the Htt gene die at embryonic day 7.5 (Duyao et al., 1995; Nasir et al., 1995; Zeitlin et al., 1995). Moreover, analysis of mice expressing $<50 \%$ of wtHtt showed extensive brain abnormalities and died shortly after birth (White et al., 1997). These data suggest that Htt is an important factor during embryonic development and that its role is not restricted to the nervous system.

To assess the function of wt and muHtt in neural cells, we developed a cell culture system composed of clonal striatalderived cells overexpressing the wt or muHtt protein. We found that wtHtt has a role as a pro-survival molecule and acts upstream of caspase- 3 and downstream of pro-apoptotic $\mathrm{Bcl}-2$ proteins. We 
also found that toxicity of the poly-Q expansion is modulated by the length of Htt backbone.

\section{MATERIALS AND METHODS}

Constructs and transfections. FLwt [FL-23Q] and FLmu [FL-82Q] (Cooper, 1998), N548wt [nt1955-15] and N548mu [nt1955-128] (Hackam, 1998), myc-tagged N63wt [N63-18Q] and N63mu [N63-82Q] (Cooper, 1998) were subcloned into pLXSP vector or cotransfected with $\mathrm{pLXSP}$ as previously described (Cattaneo et al., 1996a). Briefly, ST14A cells were grown routinely at $33^{\circ} \mathrm{C}$ in the presence of DMEM supplemented with $10 \%$ fetal bovine serum as described (Cattaneo and Conti, 1998). Ten micrograms of cDNA were transfected using calcium phosphate or lipofectamine (Life Technologies) (Cattaneo et al., 1996b). Resistant clones were selected with puromycin $3 \mu \mathrm{g} / \mathrm{ml}$, expanded, and cryopreserved. Transfection with the empty plasmid was also performed. For each construct, $\sim 20$ colonies were isolated with cloning rings and analyzed.

Protein expression assay. Expression of the cDNAs was analyzed by Western Blot (WB) using antibody MAB2166 (dilution 1:2000; Chemicon, Temecula, CA), BKP1 (dilution 1:50), Ab1 (1 $\mu \mathrm{g} / \mathrm{ml}$, kindly provided by M. DiFiglia), and Ap194 (dilution 1:1000; kindly provided by A. Sharp). For N63wt and N63mu cDNAs immunoprecipitation with an anti-myc antibody (9E10, dilution 1:100; Calbiochem, La Jolla, CA) was performed after metabolic labeling of the cells. A total of $50 \mu \mathrm{g}$ of proteins was loaded in each lane. To control for loading of the gels, an anti-actin antibody (Sigma, St. Louis, MO; 1:2000) was used. All assays were performed on cells that have been cultured up to the 25th passage.

Cell counting, MTT assay, and BrDU measurement. Cells were plated in triplicates into six well plates at a density of $2 \times 10^{5} /$ well. After $8 \mathrm{hr}$ incubation at $33^{\circ} \mathrm{C}$ the cultures were washed with HBSS, the medium was replaced with serum-deprived medium (SDM; composition: F-12/ DMEM, $5 \mathrm{mg} / 1$ insulin, $100 \mathrm{mg} / 1$ transferrin, $20 \mathrm{nM}$ progesterone, $30 \mathrm{nM}$ selenite, $60 \mathrm{~mm}$ putrescine, $2 \mathrm{~mm}$ glutamine, $0.11 \mathrm{gm} / 1$ sodium pyruvate, $3.7 \mathrm{gm} / 1$ sodium bicarbonate, and $3.9 \mathrm{gm} / 1$ HEPES) and then incubated at $39^{\circ} \mathrm{C}$. At the times indicated, cells were trypsinized, resuspended in 20 ml Isoton, and counted using a Coulter Counter machine (ZM; Coulter Instruments). For MTT assays, cells were exposed to 3-[4.5-dimethylthiazol2-phenyl]-2.5-diphenyl-tetrazolium bromide, and release of formazan from mitochondria was quantified at $560 \mathrm{~nm}$ using an ELISA plate reader. 3-Nitro-propionic acid was obtained from Sigma.

For quantitation of the mitotic events, a $6 \mathrm{hr}$ pulse of bromodeoxyuridine (BrDU; $10 \mu \mathrm{M}$, Sigma) was given to the cells (Cattaneo et al., 1994). At the end of incubation, cells were rinsed, fixed for $15 \mathrm{~min}$ in $4 \%$ paraformaldehyde, permeabilized with $0.5 \%$ Triton X-100 for 5 min, and then incubated with anti-BrDU antibody (Becton Dickinson, Mountain View, CA; 1:50) (Magrassi et al., 1998).

Secondary FITC conjugated antibody to (Sigma) was used at 1:200. The cells were viewed with a Zeiss (Axiovert) microscope, and positive cells were scored manually.

DNA fragmentation and caspase activity. Cells were harvested in $10 \mathrm{~mm}$ Tris, pH 8, 20 mm EDTA, and 2\% Triton X-100. Low molecular weight DNA was extracted by phenol/chloroform extractions and DNA precipitated with isopropanol. DNA fragmentation was detected on a $1 \%$ agarose gel.

Measurement of caspase- 3 activity: samples of $1-2 \times 10^{6}$ cells were rinsed in cold PBS and lysed in a buffer containing $25 \mathrm{~mm}$ HEPES, $\mathrm{pH}$ 7.5, $5 \mathrm{~mm}$ EDTA, $1 \mathrm{~mm}$ EGTA, $5 \mathrm{~mm} \mathrm{MgCl}, 5 \mathrm{~mm}$ dithiothreitol, $1 \%$ 3-[-(3-cholamidopropyl)dimethylammonio]-1-propanesulfonic acid (CHAPS), $10 \mu \mathrm{g} / \mathrm{ml}$ pepstatin and leupeptin, and $1 \mathrm{~mm}$ PMSF. The cell lysates were centrifuged (for $3 \mathrm{~min}$ at $5000 \mathrm{rpm}$ ), and the supernatants stored at $-80^{\circ} \mathrm{C}$. Lysates were incubated at $37^{\circ} \mathrm{C}$ in a buffer containing 25 mM HEPES, pH 7.5, 10\% sucrose, 0.1\% CHAPS, and $1 \mathrm{~mm}$ DTT supplemented with Ac-DEVD-7-amino-4-methylcoumarin (amc) (50 $\mu \mathrm{M})$. The increase of fluorescence after the cleavage of the fluorogenic amc moiety was monitored and then quantified in a LS50 Perkin-Elmer (Emeryville, CA) fluorimeter (excitation, $380 \mathrm{~nm}$; emission, $460 \mathrm{~nm}$ ). Protein content was assayed by the bicinchoninic acid procedure. For quantitation, standard curves using increasing concentrations of amc moiety were performed in parallel.

Constitutively active caspase-3 (Srinivasula et al., 1998) or pLXSP plasmid (as a control) were cotransfected with the EGFP-N1 plasmid (Clontech, Palo Alto, CA) in the ratio 10:1. Cell viability was determined $30 \mathrm{hr}$ after transfection by counting the ratio of green-stained cells (EGFP-positive) versus total number of cells.

TUNEL assay. 2-3 $\times 10^{5}$ cells were transfected with $250 \mathrm{ng}$ of pCMV-EGFP and $1 \mu \mathrm{g}$ of the indicated plasmids $(0.4 \mu \mathrm{g}$ for Bik and
Bak). Expression from the transiently transfected genes was confirmed by WB and found to range between 10 and 15 times above control. After 24 hr the cells and their supernatant were harvested, and terminal transferase terminal deoxynucleotidyl transferase-mediated biotinylated UTP nick end labeling (TUNEL) was essentially performed as described previously, using phycoerythrin (PE)-conjugated avidin (Gorczyca et al., 1993). Stained cells were analyzed by dual color FACS, collecting at least 10,000 events. The number of TUNEL-positive cells was estimated by gating on the EGFP-expressing cells, excluding $\geq 95 \%$ of untransfected cells. Transfection efficiencies were $\sim 30-40 \%$. The PE gate was set using vector-only transfected cells, excluding $\geq 95 \%$ of unstained cells. Background death was introduced by the transfection procedure and varied between individual experiments, but was constant within any given experiment. Therefore, background death was estimated by transfection of control protein 14-3-3 and subsequently subtracted from the data.

Statistical analysis. Data reported in Figures 3, 4, and 6 and in Results were compared using the one-way ANOVA test (a $p$ value $<0.05$ was considered significant). Statistical analysis for data reported in Figure 7 is nonparametric, and SD derives from data obtained in three different experiments.

\section{RESULTS}

\section{Expression of wt and muHtt in ST14A striatal cells}

Conditionally immortalized ST14A cells were stably transfected with full-length wt or poly-Q expanded Htt constructs (FLwt and FLmu, respectively) or with the Htt truncations (N548wt, N548mu, N63wt, and N63mu), as outlined in Figure $1 A$.

Expression of the exogenous proteins in the different subclones was confirmed by Western blot analysis (Fig. 1B) and immunocytochemistry (data not shown) using antibody MAB2166 raised against aa 181-810 of the Htt protein. As shown, a band of 340 $\mathrm{kDa}$ is visible on a $6 \%$ SDS-PAGE in the FLwt and FLmu clones. Similarly, a $72 \mathrm{kDa}$ band is present in N548wt clones, whereas N548mu shows a $115 \mathrm{kDa}$ band. This decreased electrophoretic mobility is attributable to the expanded CAG. Identical results were obtained with Ab1, BKP1, and AP194 antibodies (data not shown). Because the N63 constructs are myc-tagged, their expression was confirmed by an anti-myc antibody (Fig. 1B).

Size and stability of the exogenously expressed proteins over time was confirmed on lysates obtained from cells at the $4^{\text {th }}, 12^{\text {th }}$ and $25^{\text {th }}$ passages. A representative Western blot performed on lysates from N548wt and N548mu cells is shown in Figure 1C. As visible, the intensity of the immunoreactive band in cells bearing the wild-type or mutated protein did not decline with time in vitro, up to the $25^{\text {th }}$ passage. In addition, the size of the immunoreactive band remained the same, indicating that the poly-Q repeat is stably replicated in ST14A cells.

\section{Wt and muHtt differentially affect cell viability}

ST14A cells were derived from the embryonic striatum via retroviral transduction of the temperature-sensitive version of the Large-T Antigen (Cattaneo et al., 1994; Cattaneo and Conti, 1998). ST14A cells grow in $10 \%$ serum at the permissive temperature of $33^{\circ} \mathrm{C}$ (Fig. $2 a$ ) with a doubling time of $36 \mathrm{hr}$ (Cattaneo et al., 1996a). Shifting to the nonpermissive temperature of $39^{\circ} \mathrm{C}$ leads to degradation of the Large-T Antigen, with consequent block of cell proliferation and reversal of the phenotype back to that of a differentiating neuroblast. This was better demonstrated in in vivo transplantation studies (Cattaneo et al., 1994; Lundberg et al., 1997; Benedetti et al., 2000). When ST14A cells were exposed in vitro to $39^{\circ} \mathrm{C}$ in serum-deprived medium (SDM), cells changed morphology but also their viability decreased with time in a highly reproducible manner (Fig. $2 b$ ). In these conditions, increased cell death was observed in cells expressing the N548mu construct (Fig. 2d). In sharp contrast, cells overexpressing the 
A
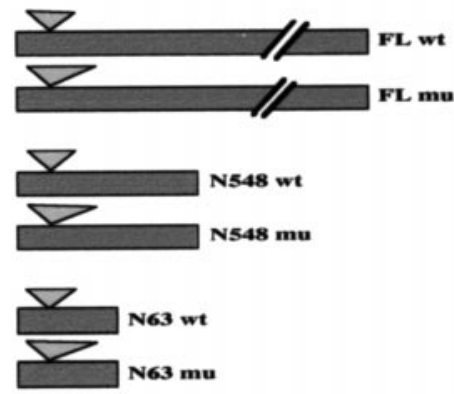
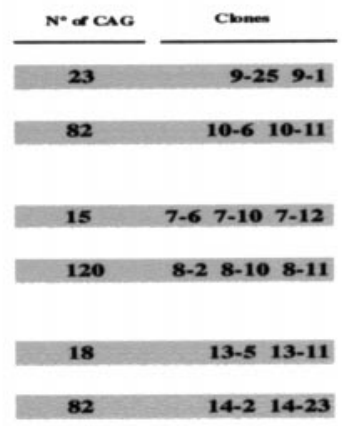

$\mathbf{B}$

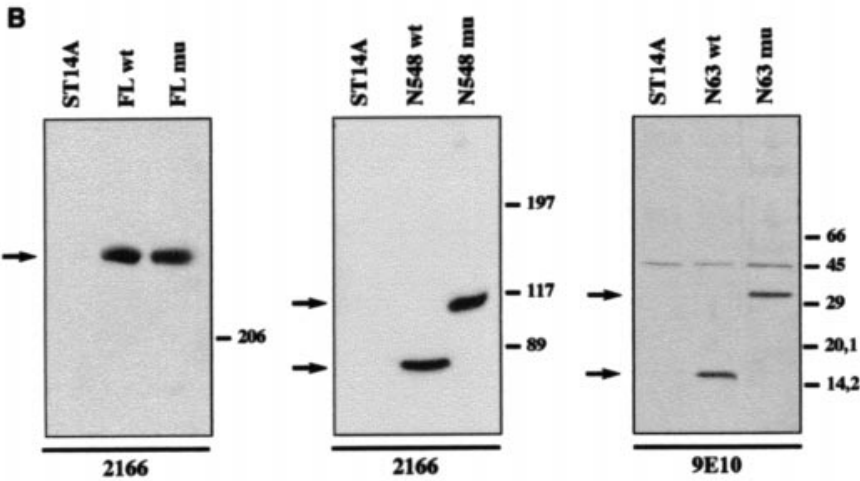

C
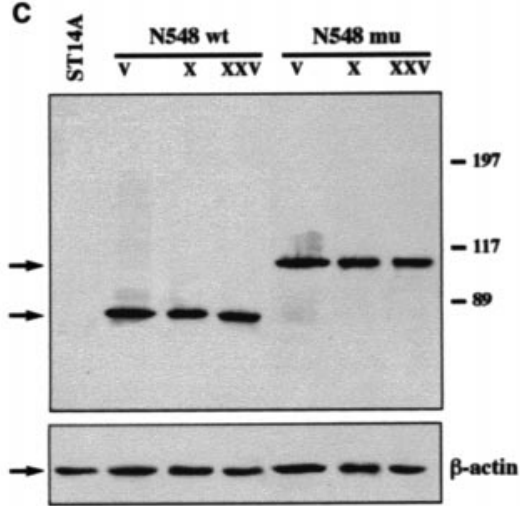

Figure 1. Expression of wt and muHtt in stable cell clones. A, Outline of the Htt constructs used and abbreviation of the stable ST14A subclones obtained. $B$, Expression of wt and muHtt in stable cell clones. Western blot analysis on lysates from clones expressing FLwt (9-25 clone), FLmu (10-6 clone), N548wt (7-12 clone), N548mu (8-2 clone), N63wt (13-5 clone), and N63mu (14-2 clone). The FL and 548aa-truncation were detected with MAB2166 after electrophoresis on a 6 or $10 \%$ SDS-PAGE, respectively. The shorter 63 aa protein was revealed by an anti-myc antibody after running the samples on a $15 \%$ SDS-PAGE. Each blot includes a lane with lysates from parental ST14A cells. Native huntingtin in the cells is detectable at longer exposures. $C$, Lysates from 7-12 and 8-2 clones were analyzed for protein expression after 5, 10, and 25 passages in vitro. Equal loading was confirmed by reacting the membrane with an anti-actin antibody.

N548wt cDNA remained viable in the same culturing conditions (Fig. 2f).

Quantitations of these effects by Coulter Counter (Fig. 3a,b) and MTT (which measures cell viability and/or mitochondrial activity; Fig. $3 c, d$ ) assays confirmed that all clones behaved approximately the same in normal growth conditions (Fig. 3a,c). However, when challenged by serum deprivation at $39^{\circ} \mathrm{C}$, significant differences in cell viability and mitochondrial activity were
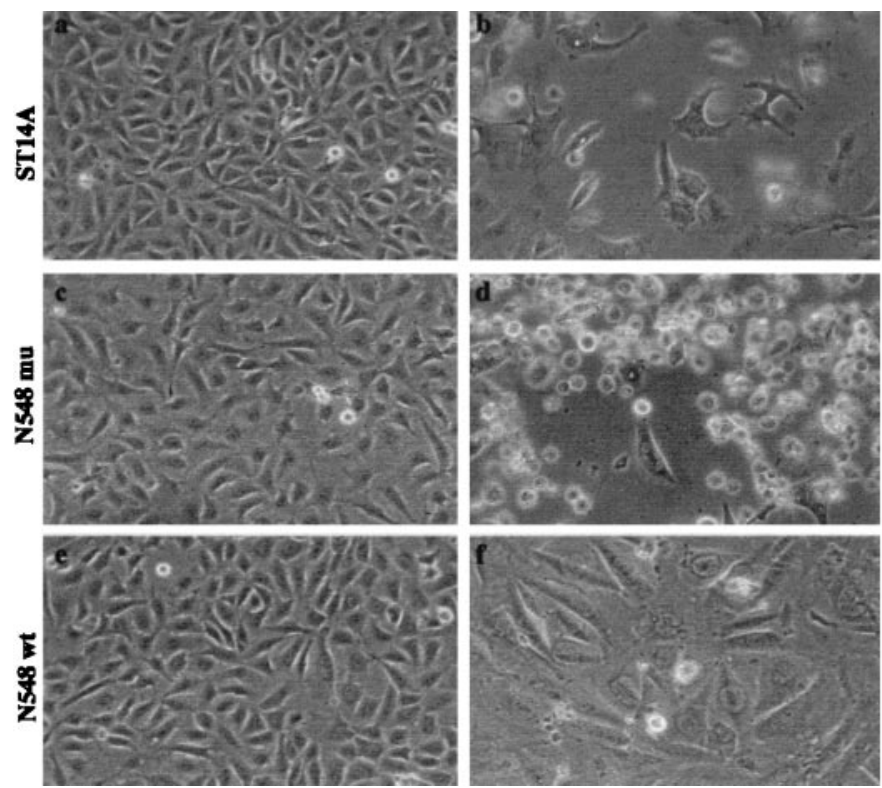

Figure 2. Morphology and confluency of parental ST14A $(a, b)$, N548mu (8-2 clone) $(c, d)$, and N548wt (7-12 clone) $(e, f)$ cells in regular passaging conditions (i.e., at $33^{\circ} \mathrm{C}$ in serum; $a, c, e$ ) and after exposure to serum-deprived medium at $39^{\circ} \mathrm{C}$ for $48 \mathrm{hr}(b, d, f)$. N548wt evokes increased cell survival, whereas N548mu leads to higher cell death in the cultures with respect to parental ST14A cells.

measured (Fig. 3b,d). ST14A cells (open squares) show, in both assays, the typical decrease in cell viability. This effect was more rapid in N548mu cells (open circles). Remarkably however, when N548wt was overexpressed (open diamonds), cell viability was maintained even at $72 \mathrm{hr}$, and decreased only at longer time points $(96 \mathrm{hr}$ ). Analysis of protein levels at these later time points at $39^{\circ} \mathrm{C}$ revealed that the decrease in cell viability correlated with a reduction in the level of the exogenous protein (data not shown), further confirming the relationship between expression of wtHtt and the phenotype observed. This correlation was further substantiated by the finding that subclones that did not express the exogenous proteins behaved as parental ST14A cells.

To exclude the possibility that increased cell number in the presence of N548wt was caused by cell proliferation, a 6 hr BrDU pulse was given to cells exposed to $39^{\circ} \mathrm{C}$ for 48 or $72 \mathrm{hr}$. We found that parental, wt, and muHtt-expressing cells divided with the same rate at $33^{\circ} \mathrm{C}$ but, no division was detected at $39^{\circ} \mathrm{C}$ in all clones, including N548wt cells (data not shown). As expected, all clones were also negative for the Large-T Antigen at $39^{\circ} \mathrm{C}$ (data not shown). These data indicate that N548wt acts by increasing cell survival and not cell division.

The pro-survival effect of wtHtt was observed in cells bearing the N548wt construct. Analogously, expression of FLwt under the same conditions produced a similar protective effect (Fig. 3d, asterisk). In contrast, cells expressing a shorter N63 cDNA in the wt form (Fig. 3d, filled diamond) were not protected and showed the same profile as parental cells. These data indicate that the protective effect of wtHtt requires a segment of the protein between aa63 and aa548.

Finally, exposure of the cells to another stress stimulus, 3-nitropropionic acid (3-NP), an inhibitor of complex I activity, revealed a similar protective effect in N548wt and FLwt cells compared to parental ST14A cells. Figure 4 shows that cultures of parental ST14A cells exhibited a dose-dependent decrease in cell 

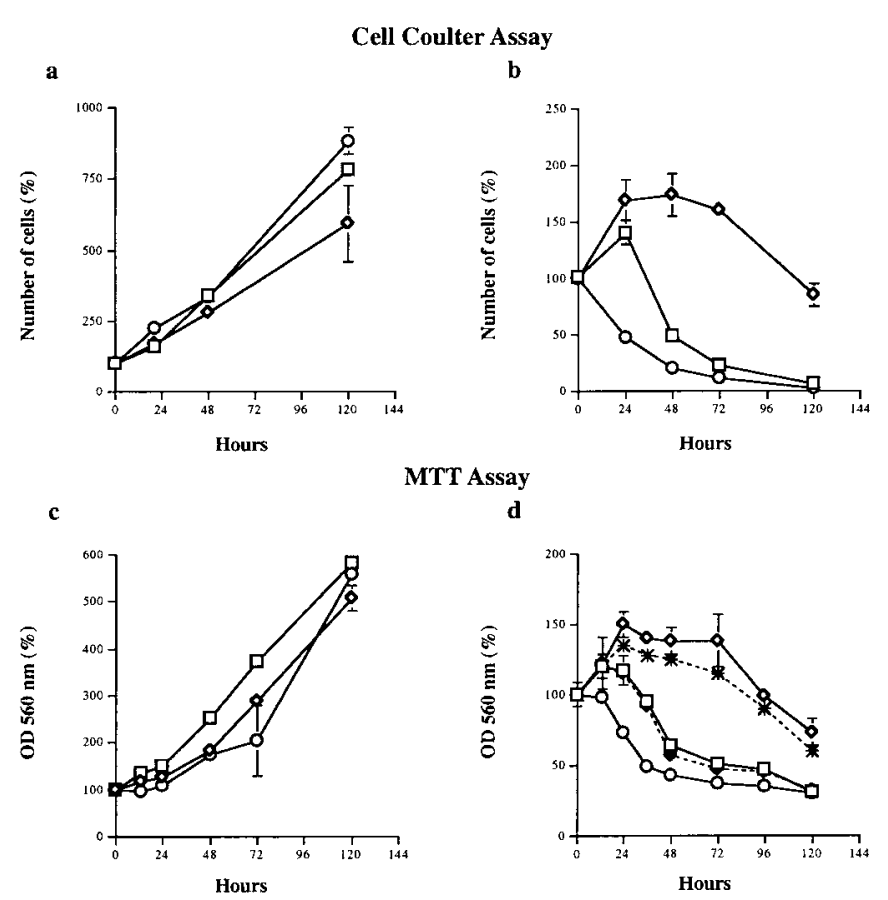

Figure 3. Coulter counter $(a, b)$ and $\operatorname{MTT}(c, d)$ assays on parental ST14A (open square), N548mu (open circle), and N548wt (open diamond) cells. $a$ and $c$ refer to the normal passaging conditions, i.e., $33^{\circ} \mathrm{C}$ in serum. $b$ and $d$ indicate the values obtained after exposure at $39^{\circ} \mathrm{C}$ in SDM. The graphs show the mean and SE of MTT assays $(n=12$ independent experiments) and Coulter counter assays $(n=4$ independent experiments) performed on three clones expressing N548wt and on two clones bearing the N548mu cDNA. Two clones expressing N63wt (filled diamond) and two expressing FLwt (asterisk) were analyzed by the same assay. All these clones behaved as parental ST14A cells in normal passaging conditions.

viability and/or mitochondrial activity by MTT assay after 1 and $5 \mathrm{~mm} 3-\mathrm{NP}$. This decrease was more evident in N548mu cells. However, cells from a representative clone expressing N548wt were almost completely protected by the action of the toxin. The same was observed in other two N548wt clones (data not shown) and in cells bearing the FLwt protein (Fig. 4). We concluded that wtHtt can protect from mitochondrial toxins.

\section{MuHtt induces, whereas wtHtt prevents, apoptotic cell death}

To determine if the cell death observed in the presence of N548mu is attributable to apoptosis and if N548wt (and FLwt) prevented DNA fragmentation, we performed the temperature shift experiment, followed by DNA analysis or Hoechst staining. As visible in Figure 5A, ST14A cells showed DNA laddering at 20 hr after the shift. Consistent with the above data, the appearance of the laddering occurred in N548mu at 1 and $4 \mathrm{hr}$ after the shift. Remarkably however, cells expressing the N548wt showed no DNA laddering even at $20 \mathrm{hr}$ after the shift. Similarly, Figure $5 B$ shows that cultures of cells expressing N548mu $(d)$ present an higher percentage of nuclei with condensed DNA with respect to parental ST14A cells. This phenomenon was not observed in N548wt cells $(f)$. These results together indicate that wtHtt directly influences cell survival and acts as an anti-apoptotic protein in neural cells.

The data reported so far also indicate that N548mu exacerbates apoptotic cell death in ST14A cells. As discussed later, however, Flmu cells behave differently from N548mu cells.
$\mathbf{A}$

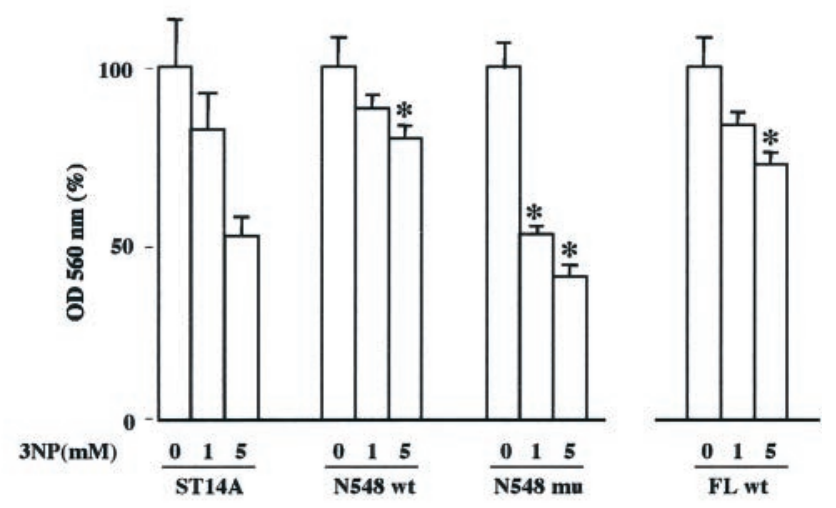

B

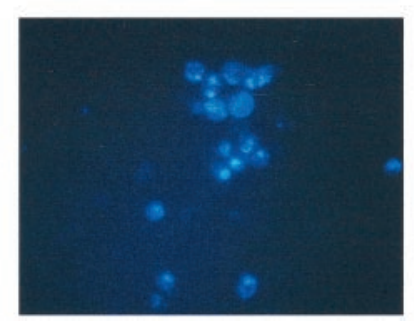

Figure 4. A, Modification in cell viability and/or mitochondrial activity after 3-NP exposure. Cells were exposed to the indicated doses of 3-NP and analyzed after $48 \mathrm{hr}$ by MTT assay. Parental ST14A cells and representative clones expressing N548wt or N548mu are shown. Protection from 3-NP is also seen in FLwt cells $\left({ }^{*} p<0.05\right.$ with respect to parental cells). Shown is one of three independent experiments performed on the different clones that gave the same results. $B$, Hoechst 33258 staining of the supernatant from ST14A cells shows that 3-NP exposure induces apoptotic cell death.

\section{WtHtt prevents caspase- 3 activation by acting at the level of caspase-9}

In search of the molecular target of wtHtt action, we first analyzed whether wtHtt affected the activity of the caspase cascade. We therefore examined the effect of the temperature shift on the activity of the effector caspase-3. Figure $6 A$ shows caspase-3-like activity measured by monitoring the release of the fluorogenic amc moiety from the caspase-3-specific substrate Ac-DEVD-amc. As shown, parental ST14A cells have a low basal level of caspase3-like activity in normal growth conditions. Exposure of the cells to $\mathrm{SDM}$ at $39^{\circ} \mathrm{C}$ led to an increase in activity, in good agreement with the tendency of ST14A cells to undergo apoptotic cell death in these conditions. Under the same conditions, a twofold to fivefold greater activity was measured in N548mu cells. Most significant, the N548wt-expressing cells had a lower level of caspase-3-like activity than in the parental line throughout the duration of the experiment (Fig. 6A), in agreement with the observations presented above. Similar results were obtained with two other clones expressing N548wt or with the clones expressing FLwt Htt. These data indicate that wtHtt acts by inhibiting caspase-3-like activation. To further demonstrate this point, parental ST14A and cells bearing N548wt or FLwt Htt were transiently cotransfected with a constitutively active caspase-3 construct and the EGFP plasmid. As shown in Figure $6 B$, transfection of active caspase- 3 kills all cells efficiently independent of upstream signaling and, according to our data, after the site where wtHtt exerts its protective effect. 


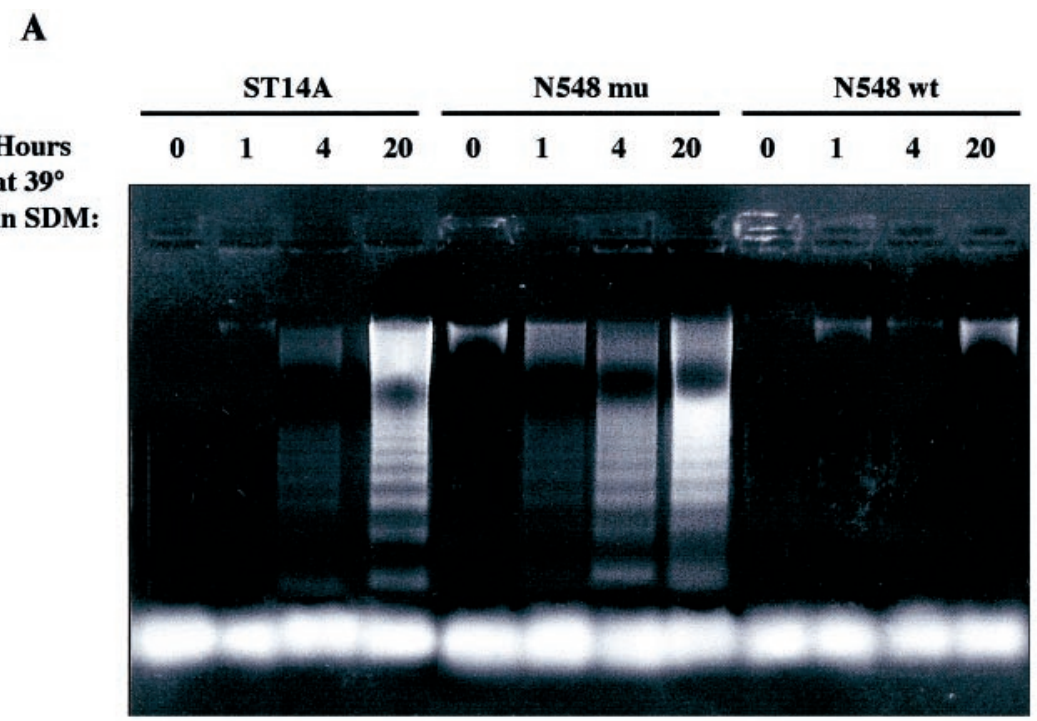

B
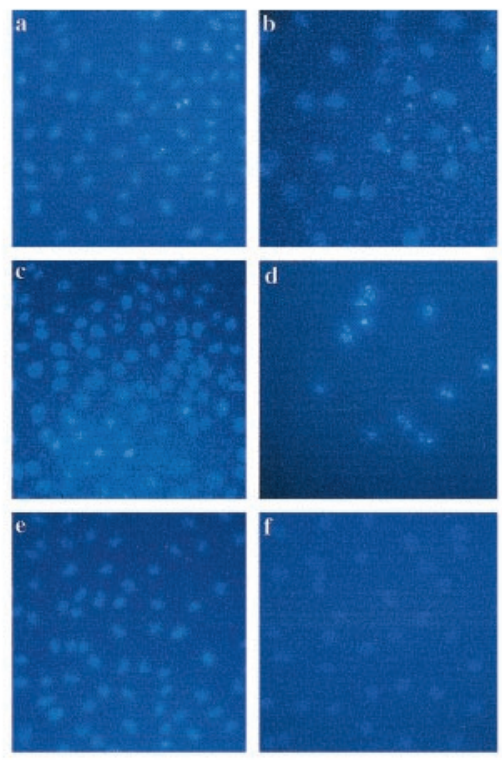

Figure 5. A, DNA laddering analysis in ST14A cells, in N548mu cells (8-2 clone), and N548wt cells (7-12 clone) after the temperature and serumdeprived medium shift. Low molecular weight DNA samples were prepared 1 , 4 , and $20 \mathrm{hr}$ after the shift. As a control, samples from cells in normal growth conditions $\left(33^{\circ} \mathrm{C}\right)$ were included $(0$ time $)$. These data were replicated in another independent experiment. $B$, Hoechst 33258 staining of parental ST14A $(a, b), \mathrm{N} 548 \mathrm{mu}(c, d)$, and N548wt $(e, f)$ cells at $33^{\circ} \mathrm{C}(a, c, e)$ and $39^{\circ} \mathrm{C}$ $(b, d, f)$. A higher number of cells with condensed DNA is visible in N548mu cells $(d)$ with respect to controls (parental ST14A, $b$ ). No DNA condensation is observed in N548wt cells $(f)$.

reflecting the tight control normally exerted on caspase-3 cleavage in these and other cells (Srinivasula et al., 1998). We concluded that expression of the poly-Q expanded protein conferred caspase-3 processing ability selectively in N548mu and Flmu cells. Finally, Figure 7 also shows that expression of $\mathrm{Bcl}_{\mathrm{XL}}-\mathrm{Bcl}_{2}$ associated death promoter (BAD) produced an increase in TUNEL-positive cells only in clones expressing muHtt constructs. This indicates that muHtt toxicity feeds into a pathway that requires BAD or a BAD-like function and argues against a direct activation of caspase-3.

\section{FImu cells are killed by fewer stimuli compared to N548mu cells}

Of note and surprisingly, whereas FLmu and N548mu cells were both as efficiently killed by caspase-3 or BAD transfection, FLmu cells were found to be resistant to other stress stimuli. For example, in contrast to N548mu cells (Fig. 3), exposure of FLmu cells for various periods of time to SDM at $39^{\circ} \mathrm{C}$ did not evoke increased cell demise compared to parental cells (absorbance ratio at various time points after exposure to $\mathrm{SDM}$ at $39^{\circ} \mathrm{C}$ with mutant expressing cells efficiently (Fig. 7). The same construct was inefficient in parental or wtHtt-expressing cells (Fig. 7),

\section{The caspase-3 zymogen and $\mathrm{Bcl}_{\mathrm{XL}}-\mathrm{Bcl}_{2}$-associated death promoter synergize with the mutation}

Interestingly, whereas transfection of most death inducers had similar effects in parental ST14A, N548mu, or Flmu cells, transfection of the zymogen (inactive) form of caspase-3 killed the 
$\mathbf{A}$

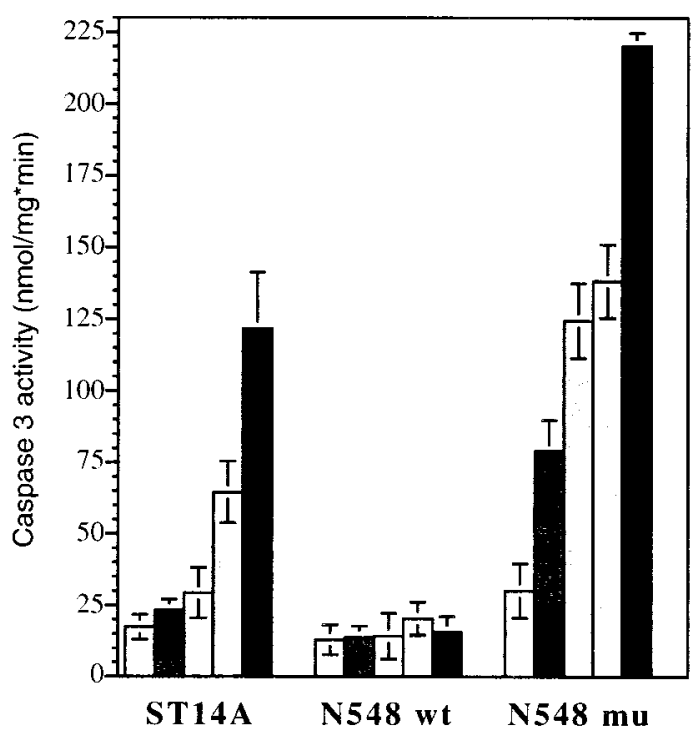

B

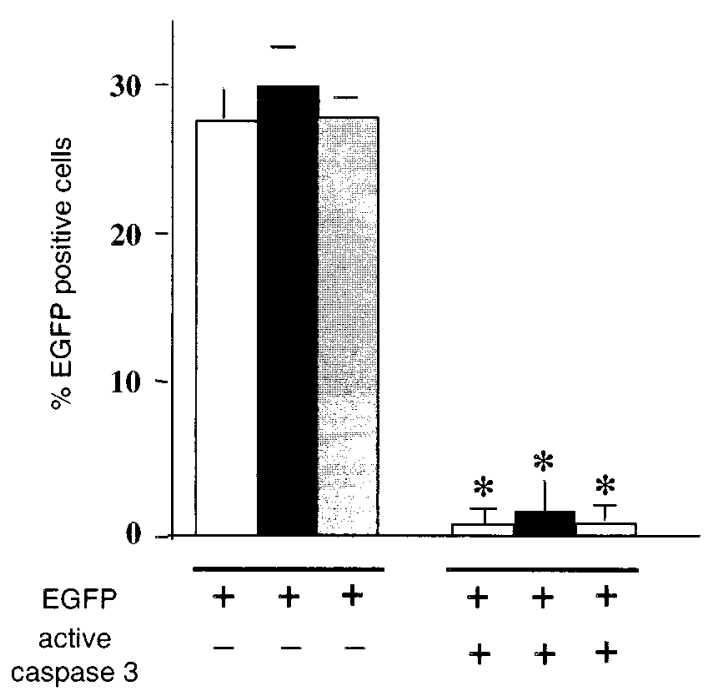

Figure 6. A, Measurement of caspase-3-like activity. The release of the fluorogenic amc moiety from the caspase-3-specific substrate Ac-DEVDamc is reported at various times $(0,3,6,9$, and $12 \mathrm{hr})$ after the temperature shift. Basal levels of caspase-3 (time 0, white bar) were obtained at $33^{\circ} \mathrm{C}$. Data are expressed as nanomoles of cleaved substrate. Shown is one of three experiments performed on different clones that gave similar results. $B$, Cotransfection of a constitutively active caspase- 3 together with the EGFP plasmid in parental ST14A (open bars), N548wtHtt (black bars), and FLwtHtt (gray bars) cells. Cells were transiently cotransfected with the active caspase- 3 or a control vector (pLXSP) together with the EGFP-N1 plasmid (Clontech). Cell viability was determined $30 \mathrm{hr}$ after transfection by counting the ratio of fluorescent cells (EGFP-positive) versus total number of cells $\left({ }^{*} p<0.01\right.$ vs EGFP vector). Data represent the mean of three independent experiments.

respect to $\mathrm{T}_{0 \mathrm{hr}}$, parental ST14A cells: $\mathrm{T}_{2 \mathrm{hr}} 100 \pm 7.4 ; \mathrm{T}_{32 \mathrm{hr}} 82.3 \pm$ $3.3 ; \mathrm{T}_{48 \mathrm{hr}}=48.0 \pm 1.8$; Flmu cells, $10-6$ clone: $\mathrm{T}_{2 \mathrm{hr}}=100 \pm 7.3$; $\mathrm{T}_{32 \mathrm{hr}}=100.3 \pm 11.7 ; \mathrm{T}_{48 \mathrm{hr}}=58.1 \pm 6.1$; Flmu cells, $10-11$ clone: $\left.\mathrm{T}_{2 \mathrm{hr}}=100 \pm 11.2 ; \mathrm{T}_{32 \mathrm{hr}}=84.9 \pm 1.9 ; \mathrm{T}_{48 \mathrm{hr}}=57.7 \pm 0.8\right)$.

Similarly, 3-NP exposure produced a decrease in cell viability and/or mitochondrial activity in N548mu cells (Fig. 4) but was inefficient in Flmu cells (absorbance ratio in the presence of 3-NP compared to untreated cultures, parental ST14A cells: $1 \mathrm{~mm}=$ $77.1 \pm 7.3 ; 5 \mathrm{~mm}=63.1 \pm 4.2$; Flmu cells, $10-6$ clone: $1 \mathrm{~mm}=$ $83.5 \pm 6.6 ; 5 \mathrm{~mm}=65.8 \pm 4.9$; Flmu cells, $10-11$ clone: $1 \mathrm{~mm}=$ $72.4 \pm 7.0 ; 5 \mathrm{~mm}=51.9 \pm 2.7)$. These data suggest that expression of a CAG as part of the FL protein modifies its toxicity. Accordingly, cells expressing the full-length protein are susceptible to fewer death stimuli compared to cells expressing truncated versions of the mutated protein.

\section{DISCUSSION}

$\mathrm{HD}$ is caused by an expanded poly(Q) in Htt, a protein of 340 $\mathrm{kDa}$ molecular weight with cytoplasmic location, and no functional domains that was found to be crucial during embryonic development. Htt is widely distributed in the CNS, however it is unlikely that Htt plays a specific role in neuronal differentiation because $\mathrm{Htt}-/-$ embryonic stem cells turn into mature neurons in vitro in the same way as the wild-type counterparts (Metzler et al., 1999).

To address the question of the exact physiological role of wtHtt in CNS cells and whether and how it relates to muHtt action, we have obtained striatal derived cells stably expressing a wt or mu poly $(\mathrm{Q})$ stretch in the context of the full-length $\mathrm{Htt}$ protein or in the N-terminal 548aa or 63aa truncations. We show that, in this cellular system, wtHtt acts as a pro-survival molecule. This effect is observed only when full-length protein or the N548 Htt truncation is expressed. Further deletion of the protein to an $\mathrm{N}$-terminal 63aa fragment resulted in the loss of the pro-survival effect. These data indicate that the protective effect of wtHtt requires at least a segment of the protein between aa63 and aa548.

Previous work demonstrated that homozygous mice with a targeted disruption in the Htt gene do not survive to term and suffer early postimplantation embryonic lethality (Duyao et al., 1995; Nasir et al., 1995; Zeitlin et al., 1995; White et al., 1997). More recent morphometric and ultrastructural analysis performed on heterozygous mice, which survive to adulthood, identified neuronal loss with signs of apoptosis in the basal ganglia of adult animals (O'Kusky et al., 1999). In our system, we found that wtHtt specifically interferes with the cell death machinery. Serum withdrawal and exposure to mitochondrial toxins led to apoptotic death in parental cells. Mu Htt-expressing cells were sensitized to these apoptotic stimuli. In contrast, these stimuli were ineffective in cells expressing wtHtt. The data indicate that wtHtt directly influences cell survival by acting as an anti-apoptotic protein. Htt is also an important survival factor earlier in development because its absence evokes increased apoptosis in the epiblast, a structure of the embryo known to give rise to the future ectoderm (Duyao et al., 1995).

To delineate the mechanism of wtHtt anti-apoptotic function, we transiently expressed several pro-apoptotic genes in the different ST14A subclones. We found that cells expressing wtHtt were protected from cell death induced by death receptors, by the pro-apoptotic Bcl-2 family members (Bik and Bak), as well as by caspase-9. This protection from multiple apoptotic inducers implies that wtHtt acts on components of the common death effector pathway. Furthermore, the protection from pro-apoptotic Bcl-2 homologs implies that wtHtt is acting on mitochondrial or postmitochondrial apoptotic events. Once caspase- 9 is activated by the apaptosome complex consisting of Apaf- 1 and cytochrome C (Cecconi et al., 1998; Yoshida et al., 1998), it directly activates the 


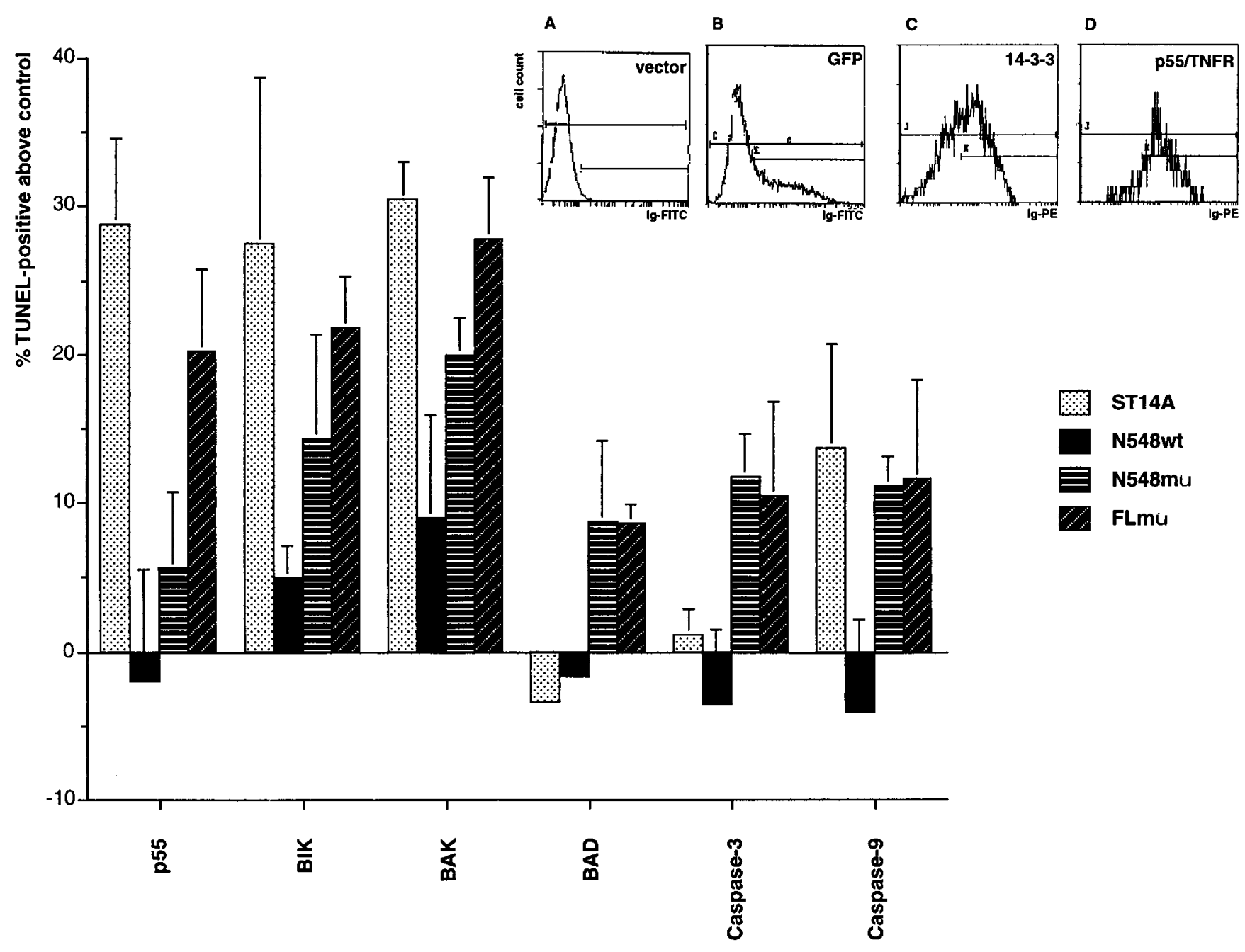

Figure 7. TUNEL of the stable cell lines expressing Htt after transfection with different death inducers. ST14A (dotted bars), N548wt (7-12 clone, black bars), N548mu (8-11 clone, horizontal striped bars), and FLmu (10-11 clone, diagonal striped bars) cells were transfected with $1 \mu \mathrm{g}$ of the indicated plasmids $(0.4 \mu \mathrm{g}$ for BIK and BAK) or a control protein. The inset depicts a typical TUNEL readout. $A$ and $B$ show gating on the EGFP-expressing cell population. $C$ shows TUNEL staining of cells transfected with the control protein; $D$ shows TUNEL staining of cells transfected with p55/TNFR. The control protein used is 14-3-3. In ST14A cells p55, BIK, BAK, and caspase-9 induce apoptosis, whereas BAD and caspase-3 show no effect. Apoptosis by all inducers is blocked in cells expressing wtHtt. FLmu cells show similar levels of apoptosis as the parental line for p55, BIK, BAK, and caspase-9 and a marked increase in BAD and caspase-3-induced apoptosis. This increase is also seen in N548mu cells. Shown is the average of three independent experiments. Error bars show the average deviation.

downstream protease, caspase-3 (Zou et al., 1999). The protection from apoptosis induced by caspase-9 transfection (Fig. 7) combined with the reduced activity of its downstream effector, caspase-3, in wtHtt cells (Fig. 6A) and to the evidence that the same cells could be killed by transfection of a constitutively active form of caspase-3 (Fig. 6B) leads us to suggest that wtHtt acts upstream of caspase- 3 and likely at the level of caspase-9 activation.

A poly $(\mathrm{Q})$ expansion in the Htt gene is suggested to produce a toxic gain-of-function effect. Accordingly, expression of muHtt induces cell death in transgenic animals and in cell culture systems (Cooper et al., 1998; Hackam et al., 1998; Lunkes and Mandel, 1998; Reddy et al., 1998; Hodgson et al., 1999). Striatalderived ST14A cells overexpressing muHtt undergo a similar fate when challenged with various stress stimuli (serum withdrawal, 3-NP exposure). In our system we found that, in the presence of muHtt, DNA fragmentation is accompanied by an increased caspase-3-like activation, which is consistently above the level found in parental ST14A cells. These data suggest that the toxic effect of muHtt converges onto caspase-3. As a further demonstration, we transfected the zymogen form of caspase-3, which normally does not lead to apoptosis (Srinivasula et al., 1998), into muHtt expressing cells and found an increase in the number of TUNEL-positive cells. Increased activation of caspase- 3 and caspase-9 was also recently reported in lymphoblasts from Huntington's disease patients exposed to chemical inducers of apoptosis (Sawa et al., 1999). Interestingly, comparisons of the phenotypes of cells expressing different muHtt constructs reveal that the toxicity of the polyglutamine repeat is modulated by the protein backbone. Indeed we found that FLmu protein promotes cell death only by selective stimuli (BAD or caspase-3 transfections), whereas N548mu truncation promotes death by a larger range of death stimuli (BAD or caspase-3 transfections, 3-NP exposure, serum withdrawal). These results highlight the possibility that truncated versions of poly $(\mathrm{Q})$ proteins induce a wider spectrum of cytotoxic events than the full-length pro- 
teins and support the notion that proteolytic cleavage is important in HD.

Further analysis of the roles and mechanisms of action of wtHtt will help to better understand its physiological functions and whether and how the $\operatorname{poly}(\mathrm{Q})$ expansion in the mutated protein interferes with those and/or other activities.

\section{REFERENCES}

Benedetti S, Pirola B, Pollo B, Magrassi L, Bruzzone MG, Rigamonti D, Galli R, Selleri S, Di Meco F, De Fraja C, Vescovi A, Cattaneo E, Finocchiaro G (2000) Gene therapy of experimental brain tumors using neural progenitor cells. Nat Med 4:447-450.

Cattaneo E, Conti L (1998) Generation and characterization of embryonic striatal conditionally immortalized ST14A cells. J Neurosci Res 53:223-234.

Cattaneo E, Magrassi L, Santi L, Butti G, Giavazzi A, Pezzotta S (1994) A short term analysis of the behaviour of conditionally immortalized progenitors and primary neuroepithelial cells implanted into the fetal rat brain. Dev Brain Res 83:197-208.

Cattaneo E, De Fraja C, Conti L, Reinach B, Bolis L, Govoni S, Liboi E (1996a) Activation of the JAK-STAT pathway leads to proliferation of ST14A CNS progenitor cells. J Biol Chem 38:23374-23379.

Cattaneo E, Conti L, Gritti A, Frolichsthal P, Govoni S, Vescovi A (1996b) Non-virally mediated gene transfer into human Central Nervous System precursor cells. Mol Brain Res 42:161-166.

Cecconi F, Alvarez-Bolado G, Meyer BI, Roth KA, Gruss P (1998) Apaf 1 (CED-4 homolog) regulates programmed cell death in mammalian development. Cell 94:727-737.

Cooper JK, Schilling G, Peters MF, Herring WJ, Sharp AH, Kaminsky Z, Masone J, Khan FA, Delanoy M, Borchelt DR, Dawson VL, Dawson TM, Ross CA (1998) Truncated N-terminal fragments of huntingtin with expanded glutamine repeats form nuclear and cytoplasmic aggregates in cell culture. Hum Mol Genet 7:783-790.

Davies SW, Turmaine M, Cozens BA, DiFiglia M, Sharp AH, Ross CA, Scherzinger E, Wanker EE, Mangiarini L, Bates GP (1997) Formation of neuronal intranuclear inclusions underlies the neurological dysfunction in mice transgenic for the HD mutation. Cell 90:537-548.

DiFiglia M, Sapp E, Chase KO, Davies SW, Bates GP, Vonsattel JP, Aronin N (1997) Aggregation of huntingtin in neuronal intranuclear inclusions and dystrophic neurites in brain. Science 277:1990-1993.

Duyao MP, Auerbach AB, Ryan A, Persichetti F, Barnes GT, McNeil SM, Kowall NW, Ge P, Vonsattel JP, Gusella JF, Joyner AL, MacDonald ME (1995) Inactivation of the mouse Huntington's disease gene homolog Hdh. Science 269:407-410.

Goldberg YP, Nicholson DW, Rasper DM, Kalchman MA, Koide HB, Graham RK, Bromm M, Kazemi-Esfajani P, Thornberry NA, Vaillancourt JP, Hayden MR (1996) Cleavage of huntingtin by apopain, a proapoptotic cysteine protease, is modulated by the polyglutamine tract. Nat Genet 13:442-449.

Gorczyca W, Gong JP, Ardelt B, Traganos F, Darzynkiewicz Z (1993) The cell-cycle related differences in susceptibility of HL-60-cells to apoptosis induced by various antitumor agents. Cancer Res 53:3186-3192.

Gutekunst CA, Li SH, Yi H, Mulroy JS, Kuemmerle S, Jones R, Rye D, Ferrante RJ, Hersch SM, Li XJ (1999) Nuclear and neuropil aggregates in Huntington's disease: relationship to neuropathology. J Neurosci 19:2522-2534.

Hackam AS, Singaraja R, Wellington CL, Metzler M, McCutcheon K, Zhang T, Kalchman M, Hayden MR (1998) The influence of huntingtin protein size on nuclear localization and cellular toxicity. J Cell Biol 141:1097-1105.

Hodgson JG, Agopyan N, Gutekunst CA, Leavitt BR, LePiane F, Singaraja R, Smith DJ, Bissada N, McCutcheon K, Nasir J, Jamot L, Li XJ, Stevens ME, Rosemond E, Roder JC, Phillips AG, Rubin EM, Hersch SM, Hayden MR (1999) A YAC mouse model for Huntington's disease with full-length mutant Huntingtin, cytoplasmic toxicity, and selective striatal neurodegeneration. Neuron 23:1-20.
Huntington's Disease Collaborative Research Group (1993) A novel gene containing a trinucleotide repeat that is expanded and unstable on Huntington's disease chromosome. Cell 72:971-983.

Kim M, Lee HS, LaForet G, McIntyre C, Martin EJ, Chang P, Kim TW, Williams M, Reddy PH, Tagle D, Boyce FM, Won L Heller A, Aronin N, DiFiglia M (1999) Mutant huntingtin expression in clonal striatal cells: dissociation of inclusion formation and neuronal survival by caspase inhibition. J Neurosci 19:964-973.

Kim TW, Tanzi RE (1998) Neuronal intranuclear inclusions in polyglutamine diseases: nuclear weapons or nuclear fallout? Neuron 21:657-659.

Kowall NW, Ferrante RJ, Martin JB (1987) Pattern of cell loss in Huntington's disease. Trends Neurosci 10:24-29.

Lundberg C, Martinez-Serrano A, Cattaneo E, McKay RDG, Bjorklund A (1997) Survival, integration and differentiation of neural stem cell lines after transplantation to the adult rat striatum. Exp Neurol 145:342-360.

Lunkes A, Mandel JL (1998) A cellular model that recapitulates major pathogenic steps of Huntington's disease. Hum Mol Genet 7:1355-1361.

MacDonald ME, Gusella J (1996) Huntington's disease: translating a CAG repeat into a pathogenic mechanism. Curr Opin Neurobiol 6:638-643.

Magrassi L, Ehrlich ME, Butti G, Pezzotta S, Govoni S, Cattaneo E (1998) Basal ganglia precursors found in aggregates following embryonic transplantation adopt a striatal phenotype in heterotopic locations. Development 125:2847-2855.

Metzler M, Chen N, Helgason CD, Graham RK, Nichol K, McCutcheon K, Nasir J, Humphries RK, Raymond LA, Hayden MR (1999) Life without huntingtin: normal differentiation into functional neurons. J Neurochem 72:1009-1018.

Nasir J, Floresco SB, O'Kusky JR, Diewert VM, Richman J, Zeisler J, Borowski A, Marth JD, Phillips AG, Hayden MR (1995) Targeted disruption of the Huntington's disease gene results in embryonic lethality and behavioural and morphological changes in heterozygotes. Cell 81:811-823.

Ona VO, Li M, Vonsattel JP, Andrews LJ, Khan SQ, Chung WM, Frey AS, Menon AS, Li XJ, Stieg PE, Yuan J, Penney JB, Young AB, Cha JH, Friedlander RM (1999) Inhibition of caspase-1 slows disease progression in a mouse model of Huntington's disease. Nature 399:263-267.

O'Kusky JR, Nasir J, Cicchetti F, Parent A, Hayden MR (1999) Neuronal degeneration in the basal ganglia and loss of pallido-subthalamic synapses in mice with targeted disruption of the Huntington's disease gene. Brain Res 818:468-479.

Reddy PH, Williams M, Charles V, Garrett L, Pike-Buchanan L, Whetsell Jr WO, Miller G, Tagle DA (1998) Behavioral abnormalities and selective neuronal loss in HD transgenic mice expressing mutated full-length HD cDNA. Nat Genet 20:198-202.

Reddy PH, Williams M, Tagle DA (1999) Recent advances in understanding the pathogenesis of Huntington's disease. Trends Neurosci 22:248-255.

Ross CA, Margolis RL, Rosenblatt A, Ranen NG, Becher MW, Aylward EA (1997) Reviews in molecular medicine: Huntington's disease and a related disorder, dentatorubral-pallidoluysian atrophy (DRPLA). Medicine 76:305-338.

Sanchez I, Xu CJ, Juo P, Kakizaka A, Blenis J, Yuan J (1999) Caspase-8 is required for cell death induced by expanded polyglutamine repeats. Neuron 22:623-633.

Saudou F, Finkbeiner S, Devys D, Greenberg ME (1998) Huntingtin acts in the nucleus to induce apoptosis but death does not correlate with the formation of intranuclear inclusions. Cell 95:55-66.

Sawa A, Wiegand GW, Cooper J, Margolis LM, Sharp AH, Lawler Jr JF, Greenamyre T, Snyder SH, Ross CA (1999) Increased apoptosis of Huntington disease lymphoblasts associated with repeat length-dependent mitochondrial depolarization. Nat Med 5: $1194-1198$.

Sharp AH, Ross CA (1996) Neurobiology of Huntington's disease. Neurobiol Dis 3:3-15.

Sisodia SS (1998) Nuclear inclusions in glutamine repeat disorders: are they pernicious, coincidental, or beneficial? Cell 95:1-4.

Srinivasula SM, Ahmad M, MacFarlane M, Luo Z, Fernandes-Alnemri T, 
Alnemri ES (1998) Generation of constitutively active recombinant caspases- 3 and -6 by rearrangement of their subunits. J Biol Chem 273:10107-10111.

Vonsattel JP, Myers RH, Stevens TJ, Ferrante RJ, Bird ED, Richardson EP Jr (1985) Neuropathological classification of Huntington's disease. J Neuropathol Exp Neurol 44:559-577.

Wellington CL, Ellerby LM, Hackam AS, Margolis RL, Trifiro MA, Singaraja R, McCutcheon K, Salvesen GS, Propp SS, Bromm M, Rowland KJ, Zhang T, Rasper D, Roy S, Thornberry N, Pinsky L, Kakizuka A, Ross CA, Nicholson DW, Bredesen DE, Hayden MR (1998) Caspase cleavage of gene products associated with triplet expansion disorders generates truncated fragments containing the polyglutamine tract. J Biol Chem 273:9158-9167.

White JK, Auerbach W, Duyao MP, Vonsattel JP, Gusella JF, Joyner
AL, MacDonald ME (1997) Huntingtin is required for neurogenesis and is not impaired by Huntington's disease CAG expansion. Nat Genet 17:404-410.

Yoshida H, Kong YY, Yoshida R, Elia AJ, Hakem A, Hakem R, Penninger JM, Mak TW (1998) Apaf 1 is required for mitochondrial pathways of apoptosis and brain development. Cell 94:739-750.

Zeitlin S, Liu JP, Chapman DL, Papaioannou VE, Esfratiadis A (1995) Increased apoptosis and early embryonic lethality in mice nullizygous for the Huntington's disease gene homologue. Nat Genet 11:155-162.

Zou H, Li Y, Liu X, Wang X (1999) An APAF-1 cytochrome c multimeric complex is a functional apaptosome that activates procaspase-9. J Biol Chem 274:11549-11556. 